\title{
Spectroscopic Studies and Applications of the Reactions of Some Anti- Diabetic and Anti-Hypertensive Drugs with Rose Bengal
}

\section{Zayed MA* and Farrag YS}

Chemistry Department, Faculty of Science, Cairo University, Giza, Egypt

*Corresponding author: Zayed MA, Chemistry Department, Faculty of Science, Cairo University, Giza, Egypt, Tel: 002-01005776675; E-mail: mazayed429@yahoo.com Received date: July 21, 2016; Accepted date: August 22, 2016; Published date: August 25, 2016

Copyright: (c) 2016 Zayed MA et al. This is an open-access article distributed under the terms of the Creative Commons Attribution License, which permits unrestricted use, distribution, and reproduction in any medium, provided the original author and source are credited.

\begin{abstract}
Simple, rapid and sensitive spectrophotometric methods were developed and validated for the microdetermination of terazosin $\mathrm{HCl}$, doxazosin mesylate and pioglitazone $\mathrm{HCl}$ drugs in pure and pharmaceutical dosage forms. These methods are based on ion-pair formation reaction between these drugs and a chromogenic reagent Rose Bengal (RBeng). These reactions were studied under various conditions and the optimum parameters were selected. The spectrophotometric microdeterminations have been done at $\lambda_{\max }=570 \mathrm{~nm}$ for terazosin $\mathrm{HCl}$ and pioglitazone $\mathrm{HCl}$ and at $\lambda_{\max }=575 \mathrm{~nm}$ for doxazosin mesylate. Under proper conditions the suggested procedures were successfully applied for microdetermination of these drugs in pure and in pharmaceutical dosage forms. The values of SD, RSD, recovery \%, LOD, LOQ and Sandell sensitivity refer to the high accuracy and precession of the applied procedures. The results obtained were compared with the data obtained by the official methods, referring to confidence and agreement with rose bengal procedure results. The solid drugs-reagent ion-pairs were prepared, separated and their structures were investigated using elemental analysis, FT-IR, ${ }^{1} \mathrm{H}-\mathrm{NMR}$ and thermal analyses and the results confirm the structures proposed by the stoichoimetric ratio in the solution work. The biological activities of the drugs and their solid ion-pairs against some types of (G-) and (G+) bacteria and fungai were studied and compared with each other. It is found that terazosin-RBeng and pioglitazone-RBeng reaction products have antibacterial effect higher than the parent drugs, but doxazosin-RBeng reaction product has almost the same antibacterial effect of the parent drug.
\end{abstract}

Keywords: Terazosin HCl; Doxazosin mesylate; Pioglitazone $\mathrm{HCl}$; Spectrophotometric microdetermination; Rose Bengal Reagent; Spectroscopic study

\section{Introduction}

Terazosin (TRZ) HCl dihydrate has an IUPAC name (1-(4-amino-6, 7- dimethoxyquinazoline-2-yl)-4-[[(2RS)-tetrahydrofuran-2-yl] carbonyl] piperazine hydrochloride dihydrate [1]) and structure given in Figure 1. It has a general formula $\mathrm{C}_{19} \mathrm{H}_{25} \mathrm{~N}_{5} \mathrm{O}_{4} \cdot \mathrm{HCl} \cdot 2 \mathrm{H}_{2} \mathrm{O}$, and mole mass $=459.9 \mathrm{~g} \cdot \mathrm{mol}^{-1}$.

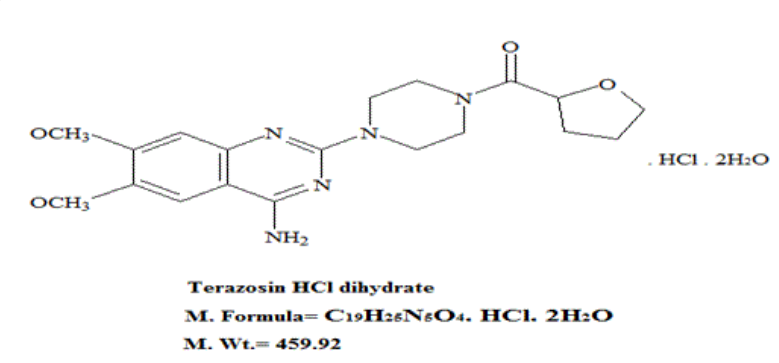

Figure 1: Structure of TRZ $\mathrm{HCl}$ dehydrate.

Doxazosin (DOX) mesylate has an IUPAC name (1-(4-amino-6, 7 dimethoxy-2- quinazolinyl)-4-[(2, 3-dihydro-1, 4-dioxin-2-yl) carbonyl] piperazine methanesulphonate) [2] and structure given by Figure 2. It has a general formula $\mathrm{C}_{23} \mathrm{H}_{25} \mathrm{~N}_{5} \mathrm{O}_{5} \cdot \mathrm{CH}_{3} \mathrm{SO}_{3} \mathrm{H}$, and mol mass $=547.6 \mathrm{~g} \mathrm{~mol}^{-1}$.

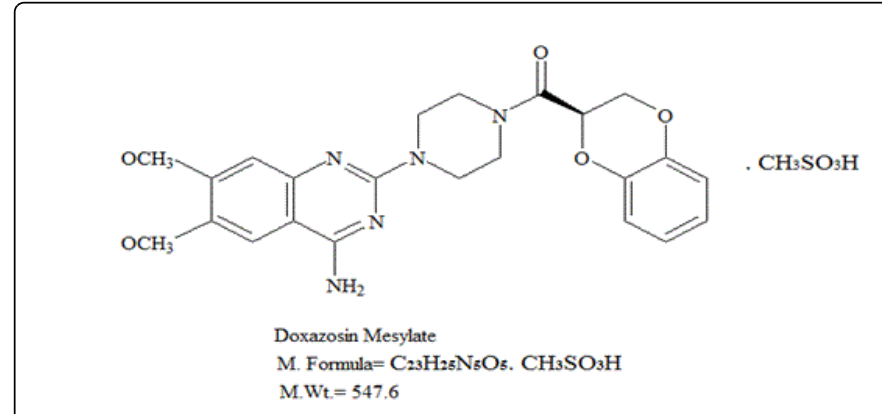

Figure 2: Structure of DOX Mesylate.

TRZ HCl dihydrate and DOX mesylate both are highly selective potent alpha-1 adrenoreceptor antagonists used in the treatment of hypertension [3] and benign prostatic hyperplasia [4,5]. The methods available for the determination of TRZ in pure, pharmaceutical and biological samples included titrimetric method [1], high performance liquid chromatography (HPLC) [3], spectrophotometric methods [6], potentiometric sensors [7] and stripping voltammetry [8].

A number of studies were described for the determination of DOX in pure, pharmaceutical and biological samples. These methods include reversed phase (RP)-HPLC [9], liquid chromatography (LC)-mass spectrometry (MS) [10], spectrophotometric methods [11] and voltammetry [12].

Pioglitazone (PIOG) HCl has an IUPAC name (5-[[4-[2-(5-Ethyl-2 pyridyl) ethoxy] phenyl] methyl]-2, 4-thiazolidinedione 
hydrochloride) and structure given in Figure 3; it has a general formula $\mathrm{C} 19 \mathrm{H} 20 \mathrm{~N} 2 \mathrm{O} 3 \mathrm{~S}$. HCl, and mol mass $=392.9 \mathrm{~g} \mathrm{~mol}^{-1}$ [13].

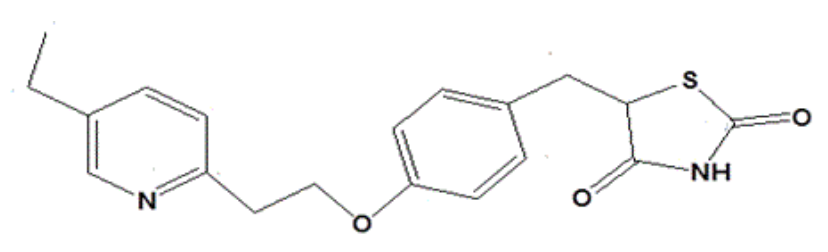

Figure 3: Structure of PIOG HCl.

PIOG is indicated as an adjunct to diet and exercise to improve glycemic control in adults with type 2 diabetes mellitus in multiple clinical settings [14]. It can also be used as a stopper in horseracing [15].

PIOG was determined in pure, pharmaceutical and biological samples using various methods alone or in a combination with other drug substances. These methods include HPLC [16], LC/MS/MS [17], spectrophotometric methods [18], Potentiometric Sensors [19], and voltammetry [20].

Rose Bengal (RBeng) dye has an IUPAC name $(4,5,6,7$ tetrachloro-2', 4', 5', 7'-tetra iodo fluorescein disodium salt) and possible structure given in Figure 4. It is an anionic water soluble xanthene dye [21].<smiles>COC(=O)c1c(Cl)c(Cl)c(Cl)c(Cl)c1-c1c2cc(I)c(=O)c(I)c-2oc2c(I)c(O[N+](=O)[O-])c(I)cc12</smiles>

Figure 4: Structure of RBeng disodium salt.

Various spectrophotometric methods were reported; where RBeng was used as a reagent for the determination of different drugs [22,23].

This present work is concerned with the spectrophotometric study of the reaction between TRZ, DOX and PIOG drugs with RBeng reagent, and how to use these reactions as new, simple and sensitive methods for the microdetermination of these drugs. It also contains spectroscopic studies on the solid reaction products for their structures investigation and a study of their biological activities.

\section{Experimental}

\section{Materials and reagents}

All chemicals used were of analytical reagent grade (AR), and of highest purity available. They included PIOG $\mathrm{HCl}$, an authentic sample was kindly supplied by Elrazy Pharmaceutical Co, Ismailia (Egypt), $\mathrm{TRZ} \mathrm{HCl}$ dihydrate and DOX mesylate, and authentic samples were kindly supplied by national organization for drug and control research (NODCAR), Cairo (Egypt). Itrin tablets (Kahira Pharm. \& Chem. IND. CO, Egypt, under license from ABBOTT Laboratories) labeled to contain $2 \mathrm{mg}$ TRZ per tablet, Dosin (EIPICO, Egypt) labeled to contain $4 \mathrm{mg}$ DOX per tablet and Glustin (Takeda Pharmaceutical Company Limited, Japan) labeled to contain $30 \mathrm{mg}$ PIOG per tablet, were collected from local market in Cairo, Egypt. RBeng disodium salt reagent was supplied from BDH Chemicals Ltd, Poole, England.

Absolute ethanol (99.8\%, Sigma Aldrich, Germany), phosphoric acid (88\%, BDH, England), acetic acid (El Salam for chemical industries, Egypt), boric acid (ADWIC), sodium hydroxide (Merck, Germany) and distilled water, obtained from all glass equipment, were used.

\section{Instruments}

The spectrophotometric measurements in solutions were carried out using Spectrophotometer, Thermo fisher scientific, model Evolution 60 v2 recording spectrophotometer, USA, UV-Vis ranged from 190 to $1100 \mathrm{~nm}$, with matched quartz cell of $1 \mathrm{~cm}$ optical length. Elemental microanalysis of the separated solid ion-pairs, for $\mathrm{C}, \mathrm{H}$ and $\mathrm{N}$ were performed in the Microanalytical Centre, Cairo University using Elementar CHNS analyzer, model Vario EL III. Infrared Spectra were recorded on FTIR 4100, Jasco spectrophotometer in wavenumber region $4000-400 \mathrm{~cm}^{-1}$. The spectra were recorded as $\mathrm{KBr}$ pellets. The ${ }^{1} \mathrm{H}$-NMR spectra were recorded with a varian-300 MHz in DMSO-d6 as solvent, where the chemical shifts were determined relative to the solvent peaks. The thermal analyses (TGA, DTG and DTA) were carried out in dynamic nitrogen atmosphere $\left(20 \mathrm{~mL} \mathrm{~min}^{-1}\right)$ with a heating rate of $10^{\circ} \mathrm{C} \mathrm{min}^{-1}$ using Shimadzu system of DTG-60H thermal analyzers.

\section{Solutions}

Stock solution of $\left(1 \times 10^{-3} \mathrm{M}\right)$ of the three drugs were prepared by dissolving the accurately weighed amount of the pure drugs $(0.0393 \mathrm{~g}$, $0.0459 \mathrm{~g}, 0.0548 \mathrm{~g}$ for PIOG, TRZ and DOX, respectively) in the appropriate volume of absolute ethanol for PIOG, distilled water for TRZ and (ethanol: distilled water) mixture (1:3) for DOX and the volume was completed to $100 \mathrm{~mL}$ volumetric flask. Diluted solutions were prepared by accurate dilution from the stock solutions to get the desired concentrations. Solution of $1 \times 10^{-3} \mathrm{M}$ RBeng disodium salt was prepared by dissolving the accurately weighed amount in the appropriate volume of distilled water and the volume completed to 250 $\mathrm{mL}$ volumetric flask.

The universal buffer $(0.04 \mathrm{M}$ acid mixture of acetic, boric and phosphoric acids) solutions of different $\mathrm{pH}$ values (2.00 to 11.05 ) were prepared as recommended by Britton and Robinson [24].

\section{Sample Solutions}

Ten tablets of Itrin $(2 \mathrm{mg} / \mathrm{tablet})$ and Glustin $(30 \mathrm{mg} / \mathrm{tablet})$ were powdered well separately. Equivalent amount of powder to two tablets of Itrin and one tablet of Glustin were weighed and dissolved in sufficient amount of distilled water and absolute ethanol, respectively, with gentle warming. The resulting solutions were filtered. The solutions were transferred to $100 \mathrm{~mL}$ volumetric flask after cooling and the volume completed to the mark with the appropriate solvent.

For dosing (4 mg/tablet), 20 tablets were powdered well. Equivalent amount of powder to 2 tablets were weighed and dissolved in about 60 
$\mathrm{mL}$ ethanol with gentle warming for $30 \mathrm{~min}$. The resulting solutions were filtered. Ethanol was evaporated to volume equal to $5 \mathrm{~mL}$. The solution was transferred to $100 \mathrm{~mL}$ volumetric flask after cooling and the volume completed to the mark with distilled water and filtered if necessary.

\section{Procedures}

Selection of suitable wavelength procedure: The spectra of $1 \times 10^{-4} \mathrm{M}$ of the three drugs and $0.25 \times 10^{-4} \mathrm{M}$ of RBeng were measured separately at $200-400 \mathrm{~nm}$, and $450-650 \mathrm{~nm}$, respectively in order to determine the $\lambda_{\max }$ of each of them. On the other hand $1 \mathrm{~mL}$ of $10^{-3} \mathrm{M}$ solution of RBeng was added to $1 \mathrm{~mL}$ of $10^{-3} \mathrm{M}$ solution of the standard drugs solution in $10 \mathrm{~mL}$ measuring flask. The mixture obtained was scanned in the wavelength range 450-650 $\mathrm{nm}$ using the reagent as a blank in order to determine the $\lambda_{\max }$ of the formed products.

Selection of suitable $\mathrm{pH}$, time and temperature procedures: To select the optimum $\mathrm{pH}$ value; the spectra of mixture of $1 \times 10^{-4} \mathrm{M}$ of the standard drugs and $1 \times 10^{-4} \mathrm{M}$ of RBeng were measured at $450-650 \mathrm{~nm}$ using the reagent as a blank at different $\mathrm{pH}$ values using buffer solutions. A suitable amount of ethanol was added to the solutions to dissolve any formed precipitates. To select the optimum time and temperature; these mixtures were measured also at different time intervals and different temperature values using the reagent as a blank.

Effect of ethanol volume: Effect of ethanol volume was studied on DOX reaction product with RBeng; where different volumes of ethanol (0.5-5 mL) were added to mixture of $1 \times 10^{-4} \mathrm{M}$ of the standard drug and $1 \times 10^{-4} \mathrm{M}$ of RBeng. The spectrophotometric measurements were recorded using the reagent as a blank to select the optimum ethanol volume.

The stoichiometric ratio of reaction: The stoichiometry of these reactions was also studied applying Job's continuous variation method (CVM) [25] and molar ratio method (MRM) [26].

Calibration curve: RBeng solution $\left(1 \times 10^{-3} \mathrm{M}\right)$ was added to variable concentrations of the standard drugs (4.599-41.39 $\mu \mathrm{g} \mathrm{mL} \mathrm{m}^{-1}$, 10.95-54.76 $\mu \mathrm{g} \mathrm{mL}^{-1}$ and 11.79-31.43 $\mu \mathrm{g} \mathrm{mL}^{-1}$ for TRZ, DOX and PIOG, respectively) under proper selected conditions and the volume was completed to $10 \mathrm{~mL} \mathrm{H}_{2} \mathrm{O}$. The absorbance was plotted against drugs concentrations at selected $\lambda_{\max }=570 \mathrm{~nm}$ for TRZ and PIOG and $575 \mathrm{~nm}$ for DOX.

Within- and In-between-day measurements: The effect of long time on the spectra of the standard drugs was carried out on five replicate experiments, at different concentrations of the standard drugs under the proper selected conditions.

Application of suggested procedures: The suggested procedures were applied for microdetermination of TRZ, DOX and PIOG in pharmaceutical Itrin, Dosin and Glustin Tablets, respectively using RBeng reagent in comparison with the official methods $[6,27,28]$ respectively. To variable concentrations of the drugs in their pharmaceutical forms (3.334-10.00, 14.55-33.96 and 13.84-24.91 $\mu \mathrm{g}$ $\mathrm{mL}^{-1}$ for TRZ, DOX and PIOG, respectively) RBeng was added under previously mentioned proper selected conditions. The spectra of the obtained mixtures were measured applying the suggested procedures.

Preparation of the solid drugs-reagent ion-pairs: The solid ion-pairs of TRZ, DOX and PIOG drugs with RBeng were prepared, by addition of a warm solution of appropriate weight of RBeng of $0.5088 \mathrm{~g}(0.5$ $\mathrm{mmol}$ ), dissolved in least amount of water; to warm solutions of 0.2300 $\mathrm{g}(0.5 \mathrm{mmol}) \mathrm{TRZ}, 0.2738 \mathrm{~g}(0.5 \mathrm{mmol}) \mathrm{DOX}$, dissolved in least amount of water and $0.1965 \mathrm{~g}(0.5 \mathrm{mmol})$ PIOG, dissolved in least amount of ethanol. The resulted solid ion-pairs were appeared as precipitates. These precipitates leaved with gentle warming for $10 \mathrm{~min}$, filtered, dried and recrystallized from ethanol. The melting points of these ion-pairs were measured.

\section{Results and Discussion}

\section{Spectrophotometric studies on the reaction of RBeng with the selected standard drugs}

Figure 5 shows the spectra of: RBeng $0.25 \times 10^{-4} \mathrm{M}$ and TRZ $\left(10^{-4} \mathrm{M}\right)$ - RBeng $\left(10^{-4} \mathrm{M}\right)$, PIOG $\left(10^{-4} \mathrm{M}\right)$ - RBeng $\left(10^{-4} \mathrm{M}\right)$, DOX $\left(10^{-4} \mathrm{M}\right)$ RBeng $\left(10^{-4} \mathrm{M}\right)$ reaction products using reagent as a blank.

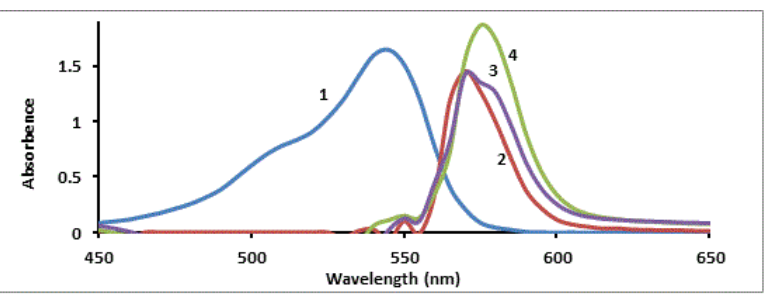

Figure 5: Vis. absorption spectra of: (1) RBeng $0.25 \times 10^{-4} \mathrm{M}$, (2) TRZ $\left(10^{-4} \mathrm{M}\right)$ - RBeng $\left(10^{-4} \mathrm{M}\right)$ reaction product, (3) PIOG $\left(10^{-4}\right.$ $\mathrm{M})$ - RBeng $\left(10^{-4} \mathrm{M}\right)$ reaction product, (4) DOX $\left(10^{-4} \mathrm{M}\right)$ - RBeng $\left(10^{-4} \mathrm{M}\right)$ reaction product.

From Figure 5, $\lambda_{\max }=570 \mathrm{~nm}$ is selected as a suitable wavelength for microdetermination of TRZ and PIOG with RBeng reagent and $\lambda_{\max }=575 \mathrm{~nm}$ is selected as a suitable wavelength for microdetermination of DOX with RBeng reagent, which are away from that of RBeng reagent $\left(\lambda_{\max }=545 \mathrm{~nm}\right)$.

Effect of $\mathrm{pH}$ (2.00-11.05) on the spectrum of TRZ-RBeng and PIOG-RBeng products was studied spectrophotometrically at $\lambda_{\max }=570 \mathrm{~nm}$. The results show that the maximum absorbance attained at pH 5 for both of them with the highest molar absorptivity, $\varepsilon=1.442 \mathrm{x}$ 104 and $1.488 \times 10^{4} \mathrm{~L} \mathrm{~mol}^{-1} \mathrm{~cm}^{-1}$ for TRZ and PIOG, respectively.

Effect of temperature was studied in the temperature range $25-70^{\circ} \mathrm{C}$ on absorption spectrum of TRZ-RBeng and PIOG-RBeng reaction products at $\lambda_{\max }=570 \mathrm{~nm}, \mathrm{pH} 5$ and in the range $26-45^{\circ} \mathrm{C}$ on absorption spectrum of DOX-RBeng reaction product at $\lambda_{\max }=575$ $\mathrm{nm}$. These results show that the optimum temperatures are found to be; room temperature $\left(25 \pm 2{ }^{\circ} \mathrm{C}\right), 35 \pm 1{ }^{\circ} \mathrm{C}$ and $30-35^{\circ} \mathrm{C}$, for TRZ, PIOG and DOX, respectively with molar absorptivity $\varepsilon=1.198 \times 10^{4}$, $1.640 \times 10^{4}$ and $2.070 \times 10^{4} \mathrm{~L} \mathrm{~mol}^{-1} \mathrm{~cm}^{-1}$, respectively.

Studying the effect of time (0-60 min.) on the formation of the three products at the selected conditions shows that the three reaction products are stable over one hour and the time has no significant effect on their stabilities.

For DOX-RBeng reaction product an extra ethanol had to be added to prevent any formation of precipitates, but this addition affects the absorbance, so ethanol volume effect was studied and the results show that the absorbance remains constant at 1.5 and $2 \mathrm{~mL}$ of ethanol, so ethanol volume of $2 \mathrm{~mL}$ is chosen as the optimum volume for the microdetermination. 
Citation: Zayed MA, Farrag YS (2016) Spectroscopic Studies and Applications of the Reactions of Some Anti-Diabetic and Anti-Hypertensive

\section{Stoichiometric ratios of drugs-RBeng reaction products}

The Stoichiometric ratio of RBeng reaction with the selected drugs, which depends on ion-pair formation, was studied by the CVM [25] and MRM [26]. The results obtained from the MRM of the reaction of RBeng with variable [TRZ] refer to stoichiometric ratio between RBeng reagent and TRZ drug, (R:D), equal to (1:1). For DOX, the results obtained from CVM and MRM of the reaction of DOX with variable [RBeng] refer to stoichiometric ratio (1:1) and the results obtained from the MRM of the reaction of RBeng with variable [DOX] refer to stoichiometric ratio, equal to $(1: 2)$.

For PIOG, the results obtained from CVM refer to stoichiometric ratio, equal to (1:1) and the results obtained from the MRM of the reaction of RBeng with variable [PIOG] refer to stoichiometric ratios, (1:1) and (1:2).

Depending upon these results; the proposed reaction for ion-pair formation between TRZ, DOX and PIOG drugs and RBeng reagent may be given by the schemes 1,2 and 3 , respectively.

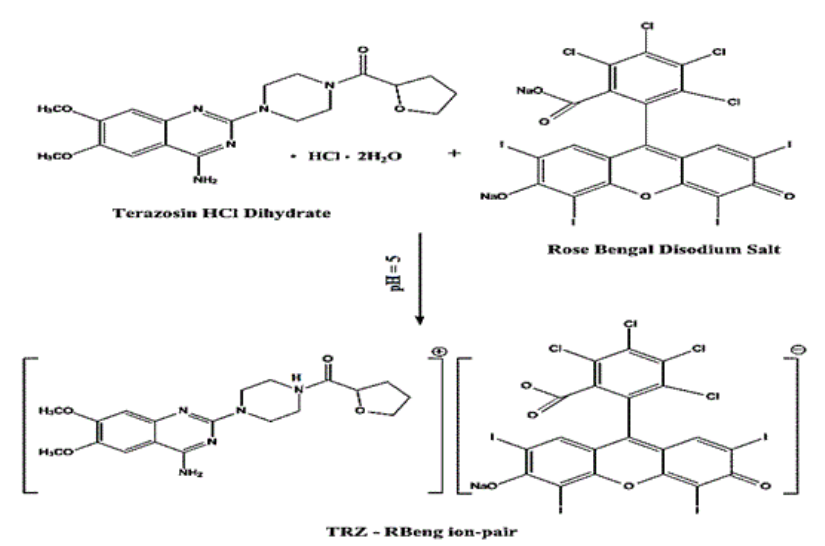

Scheme (1): Proposed reaction for TRZ-RBeng ion-pair formation

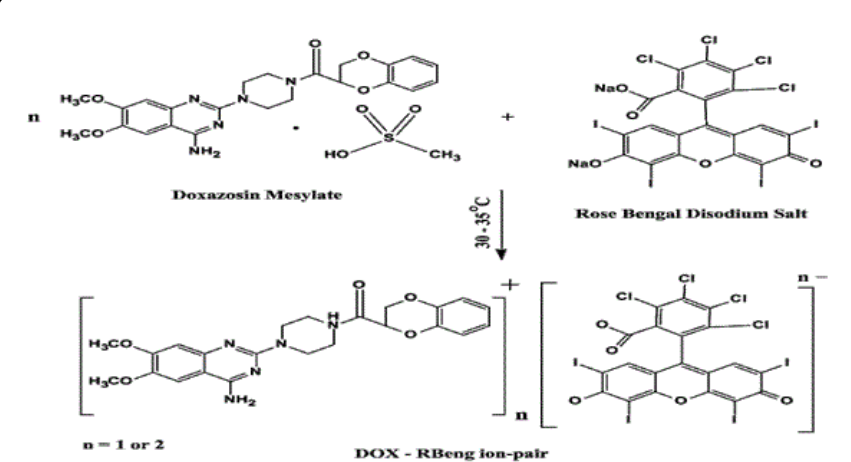

Scheme (2): Proposed reaction for DOX-RBeng ion-pair formation.

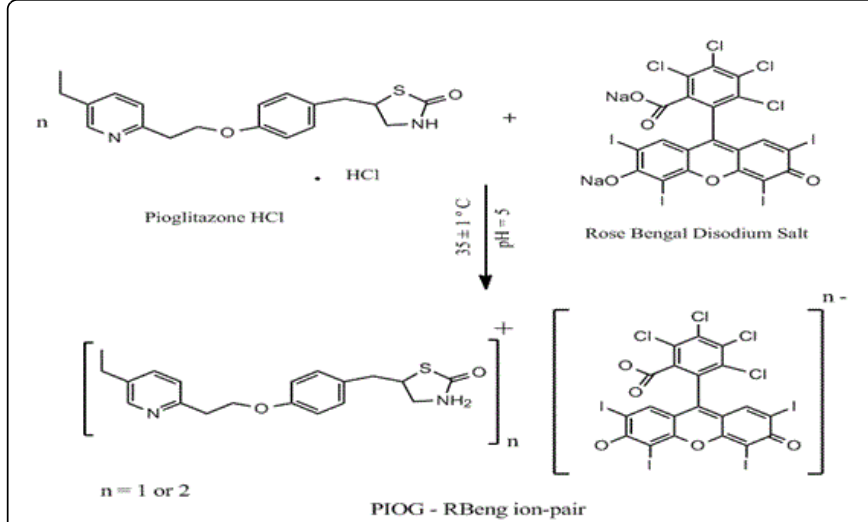

Scheme (3): Proposed reaction for PIOG-RBeng ion-pair formation.

\section{Calibration curve}

The calibration curves of TRZ, DOX and PIOG drugs and RBeng reagent were constructed by plotting the absorbance against variable concentrations of the drugs under the selected proper conditions. These calibration curves were constructed at $\lambda_{\max }=570 \mathrm{~nm}$ for TRZ and PIOG and at $575 \mathrm{~nm}$ for DOX. The results show that the three calibration curves are rectilinear in the concentration range of 4.599-41.39 $\mu \mathrm{g} \mathrm{mL}^{-1}, 10.95-54.76 \mu \mathrm{g} \mathrm{mL}^{-1}$ and 11.79-31.43 $\mu \mathrm{g} \mathrm{mL}^{-1}$, for TRZ, DOX and PIOG, respectively (Table 1).

\begin{tabular}{|c|c|c|c|c|}
\hline \multirow{2}{*}{ Parameters } & \multicolumn{4}{|l|}{ Drug } \\
\hline & TRZ & DOX & PIOG & \\
\hline Reagent & \multicolumn{4}{|l|}{ RBeng } \\
\hline Temperature $\left({ }^{\circ} \mathrm{C}\right)$ & $\begin{array}{l}\text { Room Temperature } \\
(25 \pm 2)\end{array}$ & $30-35$ & $35 \pm 1^{\circ} \mathrm{C}$ & \\
\hline$\lambda \max (\mathrm{nm})$ & 570 & 575 & 570 & \\
\hline $\mathrm{pH}$ & 5 & - & 5 & \\
\hline Linearity $\left(\mu \mathrm{g} \mathrm{mL}^{-1}\right)$ & $4.599-41.39$ & $10.95-54.76$ & $11.79-31.43$ & \\
\hline $\operatorname{LOD}\left(\mu \mathrm{g} \mathrm{mL}^{-1}\right)$ & 0.7731 & 1.303 & 1.051 & \\
\hline $\operatorname{LoQ}\left(\mu \mathrm{gL}^{-1}\right)$ & 2.343 & 3.947 & 3.184 & \\
\hline $\mathrm{R}^{2}$ & 0.9998 & 0.9994 & 0.9982 & \\
\hline $\begin{array}{l}\text { Regression } \\
\text { equation }\end{array}$ & $\begin{array}{l}Y=0.0398 x \\
0.0044\end{array}$ & $\begin{array}{l}Y=0.0334 x+ \\
0.175\end{array}$ & $\begin{array}{l}Y=0.0391 x \\
0.0861\end{array}$ & \\
\hline $\begin{array}{l}\text { Molar absorptivity } \\
\left(\mathrm{L} \mathrm{mol}^{-1} \mathrm{~cm}^{-1}\right)\end{array}$ & $1.831 \times 104$ & $1.826 \times 10^{4}$ & $1.534 \times 10^{4}$ & \\
\hline SD & $0.0503-0.1501$ & $0.0650-0.4604$ & $0.1030-0.2798$ & \\
\hline RSD \% & $0.1414-1.767$ & $0.2651-1.099$ & $0.4344-1.082$ & \\
\hline $\begin{array}{l}\text { Sandell sensitivity } \\
\left(\mu \mathrm{g} \mathrm{cm}^{-2}\right)\end{array}$ & 0.0054 & 0.0055 & 0.0065 & \\
\hline
\end{tabular}


Citation: Zayed MA, Farrag YS (2016) Spectroscopic Studies and Applications of the Reactions of Some Anti-Diabetic and Anti-Hypertensive Drugs with Rose Bengal. Pharm Anal Acta 7: 503. doi:10.4172/2153-2435.1000503

Page 5 of 10

Recovery \% $98.57-101.14$ $97.87-101.6$ $98.52-101.4$

Table 1: Analytical parameters for spectrophotometric determination of standard TRZ, DOX and PIOG drugs by proposed RBeng method.

From Table 1, the high values of the molar absorptivities $\left(1.831 \times 10^{4}\right.$, $1.826 \times 10^{4}$ and $1.534 \times 10^{4} \mathrm{~L} \mathrm{~mol}^{-1} \mathrm{~cm}^{-1}$ ) indicate the sensitivity of the proposed methods. The correlation coefficient values are found to be 0.9998, 0.9994 and 0.9982 ; which supports the linearity of the curves. Also the mean recovery values obtained are in the ranges of 98.57-101.14\%, 97.87-101.6\% and 98.52-101.4\%; which indicate the high accuracy of the applied procedures in determination of standard TRZ, DPX and PIOG drugs, respectively. The low values of standard deviation (SD) (0.0503-0.1501, 0.0650-0.4604 and 0.1030-0.2798) and relative standard deviation (RSD \%) (0.1414-1.767\%, 0.2651-1.099\% and $0.4344-1.082 \%$ ), for $n=5$, indicate the high precision of the applied procedures under the selected proper conditions. The values of the limit of detection (LOD) are found to be $0.7731,1.303$ and $1.051 \mu \mathrm{g}$ mL-1 for TRZ, DOX and PIOG, respectively, and limit of quantification (LoQ) are found to be $2.343,3.947$ and $3.184 \mu \mathrm{gL} \mathrm{LL}^{-1}$ for TRZ, DOX and PIOG, respectively. The low values of Sandell sensitivity ( $S . S=0.0054,0.0055$ and $0.0065 \mu \mathrm{g} \mathrm{cm}^{-2}$ ) refer to the high sensitivity of the proposed methods. From these parameters it is concluded that, the proposed spectrophotometric methods can be applied successfully for the determination of TRZ, DOX and PIOG drugs, respectively, in the concentration range mentioned above with a high accuracy, precision and sensitivity.

\section{Within- and In-between-day measurements}

The results obtained from within- and in-between-day measurements are shown in Tables 2 and 3, respectively.

From Tables 2 and 3, the within- and in-between-day recovery percentage, SD and RSD \% values for the three standard drugs indicate that, the proposed methods are reproducible and RBeng can be successfully applied for determination of standard TRZ, DOX and PIOG drugs via the proposed ion-pair formation reaction.

\begin{tabular}{|l|l|l|l|l|l|}
\hline \multirow{2}{*}{ Drug } & $\begin{array}{l}\text { [wt.] } \\
\text { taken }\end{array}$ & $\begin{array}{l}\text { [wt.] found }(\boldsymbol{\mu g} \\
\left.\mathbf{m L}^{-1}\right) \pm \text { SD }\end{array}$ & Recovery (\%) & SD $^{\mathrm{a}}$ & RSD (\%) \\
\cline { 2 - 6 } & $\left(\boldsymbol{\mu g} \mathbf{~ m L}^{-1}\right)$ & & & \\
\hline \multirow{2}{*}{ TRZ } & 29.18 & $28.97 \pm 0.2058$ & $98.67-100.4$ & 0.2058 & 0.7107 \\
\cline { 2 - 6 } & 34.05 & $33.44 \pm 0.3384$ & $97.55-99.59$ & 0.3384 & 1.014 \\
\hline \multirow{3}{*}{ DOX } & 32.85 & $33.09 \pm 1.085$ & $100.4-101.3$ & 1.085 & 3.279 \\
\cline { 2 - 6 } & 38.33 & $37.88 \pm 0.9191$ & $98.21-99.46$ & 0.9191 & 2.425 \\
\cline { 2 - 6 } & 47.31 & $46.56 \pm 0.9286$ & $97.50-99.33$ & 0.9286 & 1.998 \\
\cline { 2 - 6 } & 52.56 & $52.37 \pm 1.470$ & $99.13-100.5$ & 1.47 & 2.806 \\
\hline
\end{tabular}

\begin{tabular}{|l|l|l|l|l|l|}
\hline \multirow{3}{*}{ PIOG } & 25.54 & $25.69 \pm 0.3228$ & $98.99-102.7$ & 0.3228 & 1.254 \\
\cline { 2 - 6 } & 27.5 & $28.05 \pm 0.1877$ & $101.2-102.7$ & 0.1877 & 0.6694 \\
\cline { 2 - 6 } & 31.48 & $31.37 \pm 0.3707$ & $98.19-100.6$ & 0.3707 & 1.18 \\
\hline
\end{tabular}

Table 2: Within-day spectrophotometric microdetermination of standard TRZ, DOX and PIOG drugs by the proposed RBeng method. ${ }^{a}$ Mean values for six determinations for TRZ, four determinations for DOX and five determinations for PIOG, within $5 \mathrm{~h}$.

\begin{tabular}{|c|c|c|c|c|c|}
\hline \multirow{2}{*}{ Drug } & [wt.] taken & \multirow{2}{*}{$\begin{array}{l}\text { [wt.] found ( } \mu \mathrm{g} \\
\left.\mathrm{mL}^{-1}\right) \pm \mathrm{SD}\end{array}$} & \multirow{2}{*}{$\begin{array}{l}\text { Recovery } \\
\text { (\%) }\end{array}$} & \multirow{2}{*}{$\mathbf{S D}^{\mathrm{a}}$} & \multirow{2}{*}{ RSD $(\%)^{2}$} \\
\hline & $\left(\mu \mathrm{g} \mathrm{mL}^{-1}\right)$ & & & & \\
\hline \multirow{2}{*}{ TRZ } & 29.18 & $30.46 \pm 0.3421$ & $103.0-106.9$ & 0.3421 & 1.123 \\
\hline & 34.05 & $35.12 \pm 0.3524$ & 101.9-104.7 & 0.3524 & 1.002 \\
\hline DOX & 32.85 & $32.59 \pm 1.293$ & $96.68-101.6$ & 1.293 & 3.279 \\
\hline \multirow{3}{*}{ PIOG } & 25.54 & $25.36 \pm 0.3285$ & 98.13-100.4 & 0.3285 & 1.297 \\
\hline & 27.5 & $28.25 \pm 0.2658$ & $101.6-105.0$ & 0.2658 & 0.9368 \\
\hline & 31.48 & $31.41 \pm 0.6141$ & 98.19-100.6 & 0.6141 & 1.95 \\
\hline
\end{tabular}

Table 3: In-between-day spectrophotometric microdetermination of standard TRZ, DOX and PIOG drugs by the proposed RBeng method. ${ }^{a}$ Mean values of four determinations for five days for TRZ and DOX and of four determinations for six days for PIOG.

\section{Application of the applied procedures in comparison with the official methods}

The RBeng reagent was successfully applied for the microdetermination of TRZ in Itrin, $2 \mathrm{mg} /$ tablet, DOX in Dosin, $4 \mathrm{mg} /$ tablet and PIOG in Glustin, $30 \mathrm{mg} /$ tablet under proper conditions at $\lambda_{\max }=570 \mathrm{~nm}$ for TRZ and PIOG and $\lambda_{\max }=575 \mathrm{~nm}$ for DOX. The results obtained are compared with the official methods $[6,27,28]$, for TRZ, DOX and PIOG, respectively and are presented in Table 4.

From Table 4, the values of the recovery and the low values of SD of the proposed methods indicate the high accuracy and precision of the proposed methods for the microdetermination of TRZ, DOX and PIOG drugs in the pharmaceutical dosage forms. The accuracy and the precision of the proposed methods are compared with those obtained from the official methods by student's t-test and F-test, respectively, at confidence limit $95 \%$ and $\mathrm{P}=0.05$ [29]. The obtained values of F-test and $\mathrm{t}$-test indicate that there is no significant difference between the accuracy and the precision of the proposed and the official methods and hence the reliability of the proposed methods for the routine analysis of TRZ, DOX and PIOG drugs in pure and in their pharmaceutical formulations.

\begin{tabular}{|c|c|c|c|c|c|c|c|c|c|c|c|c|}
\hline \multirow{3}{*}{ Sample } & \multicolumn{5}{|c|}{ Proposed method } & \multicolumn{5}{|c|}{ Official methods } & \multirow{2}{*}{ F-test } & \multirow{2}{*}{ t-test } \\
\hline & \multicolumn{5}{|c|}{ [Drug] $\mu \mathrm{g} \mathrm{mL} \mathbf{L}^{-1}$} & \multicolumn{5}{|c|}{ [Drug] $\mu \mathrm{g} \mathrm{mL}^{-1}$} & & \\
\hline & Taken & Found & Recovery & $\mathbf{S D}^{\mathrm{a}}$ & $\begin{array}{l}\text { Mean } \quad \pm \\
\text { SD }\end{array}$ & Taken & Found & Recovery $(\%)^{b}$ & $\mathbf{S D}^{\mathrm{b}}$ & Mean \pm SD & & \\
\hline
\end{tabular}


Citation: Zayed MA, Farrag YS (2016) Spectroscopic Studies and Applications of the Reactions of Some Anti-Diabetic and Anti-Hypertensive Drugs with Rose Bengal. Pharm Anal Acta 7: 503. doi:10.4172/2153-2435.1000503

Page 6 of 10

\begin{tabular}{|c|c|c|c|c|c|c|c|c|c|c|c|c|c|c|}
\hline & & & $(\%)^{a}$ & & & & & & & & & & \multirow{6}{*}{$\begin{array}{l}1.566 \\
(6.256 \\
)^{*}\end{array}$} & \multirow{6}{*}{$\begin{array}{l}22.45 \\
(2.26)^{*}\end{array}$} \\
\hline \multirow{5}{*}{$\begin{array}{l}\text { TRZ in Itrin } \\
\text { Tablet (2mg/ } \\
\text { Tablet) }\end{array}$} & 3.334 & 3.332 & 99.93 & 0.0208 & \multirow{5}{*}{$\begin{array}{l}100.52 \quad \pm \\
0.0521\end{array}$} & 4 & 4 & 3.986 & 99.65 & 0.0367 & \multirow{5}{*}{$\begin{array}{l}99.71 \\
0.0652\end{array}$} & & & \\
\hline & 5.002 & 4.791 & 98.04 & 0.0417 & & & 8 & 7.978 & 99.73 & 0.0824 & & & & \\
\hline & 6.669 & 6.783 & 101.7 & 0.0136 & & & 12 & 11.99 & 99.95 & 0.0696 & & & & \\
\hline & 8.336 & 8.551 & 102.6 & 0.1348 & & & 14 & 13.93 & 99.5 & 0.0714 & & & & \\
\hline & 10 & 10.04 & 100.3 & 0.0498 & & & & & & & & & & \\
\hline \multirow{5}{*}{$\begin{array}{l}\text { DOX in } \\
\text { Dosin Tablet } \\
\text { (4mg/ } \\
\text { Tablet) }\end{array}$} & 14.55 & 14.66 & 100.7 & 0.1349 & \multirow{5}{*}{$\begin{array}{ll}99.56 & \pm \\
0.3463\end{array}$} & & 4 & 3.994 & 99.84 & & \multirow{5}{*}{$\begin{array}{l}99.46 \\
0.3900\end{array}$} & \multirow{5}{*}{ \pm} & \multirow{5}{*}{$\begin{array}{l}1.268 \\
(6.944 \\
)^{*}\end{array}$} & \multirow{5}{*}{$\begin{array}{l}0.3788 \\
(2.45)^{\star}\end{array}$} \\
\hline & 19.41 & 19.59 & 100.9 & 0.2691 & & & 6 & 5.938 & 98.96 & & & & & \\
\hline & 24.26 & 23.78 & 98.03 & 0.3912 & & & 8 & 7.974 & 99.68 & & & & & \\
\hline & 29.11 & 28.84 & 99.07 & 0.3712 & & & 10 & 9.934 & 99.34 & & & & & \\
\hline & 33.96 & 33.63 & 99.03 & 0.5652 & & & & & & & & & & \\
\hline \multirow{5}{*}{$\begin{array}{l}\text { PIOG in } \\
\text { Glustin } \\
\text { Tablet (30 } \\
\text { mg Tablet) }\end{array}$} & 13.84 & 13.53 & 97.8 & 0.0968 & \multirow{5}{*}{$\begin{array}{ll}100.0 & \pm \\
0.1772\end{array}$} & & 20 & 19.92 & 99.58 & & \multirow{5}{*}{$\begin{array}{l}99.79 \\
0.1976\end{array}$} & & \multirow{5}{*}{$\begin{array}{l}1.243 \\
(6.256 \\
)^{*}\end{array}$} & \multirow{5}{*}{$\begin{array}{l}1.837 \\
(2.26)^{\star}\end{array}$} \\
\hline & 16.6 & 16.65 & 100.3 & 0.2005 & & & 30 & 29.95 & 99.83 & & & & & \\
\hline & 19.37 & 19.6 & 101.2 & 0.1825 & & & 40 & 39.99 & 99.97 & & & & & \\
\hline & 22.14 & 22.29 & 100.7 & 0.2222 & & & & & & & & & & \\
\hline & 24.91 & 24.92 & 100.1 & 0.1841 & & & & & & & & & & \\
\hline
\end{tabular}

Table 4: Spectrophotometric microdetermination of TRZ, DOX and PIOG drugs in pharmaceutical formulations by proposed RBeng method. ${ }^{a}$ Average of five determinations. ${ }^{b}$ Average of six determinations for TRZ, of three determinations for DOX, ${ }^{*}$ The values between brackets are the tabulated $\mathrm{F}$ - and $\mathrm{t}$-values at $\mathrm{P}=0.05$ and confidence limit 95\% [29].

\section{Structure identification of drugs-RBeng products by different physicochemical methods of analyses}

The structures of drugs-RBeng solid ion-pairs have been identified by different physicochemical tools which are elemental analyses $(\mathrm{C}, \mathrm{H}$, and N); IR, 1H-NMR and thermal analyses (TGA, DTGA and DTA). The products spectra are compared with those of the drugs and RBeng aiming chiefly to shed light on the mechanism of the reaction between the three drugs and RBeng in solution.

\section{Elemental Analyses (EA) of the solid ion-pairs}

The elemental analyses results, analytical and physical data of RBeng-drugs ion-pairs are given in Table 5. From these data; the general formulae of the formed solid ion-pairs are determined and their mole masses are calculated.

\begin{tabular}{|c|c|c|c|c|c|}
\hline \multirow{3}{*}{ Ion-pair } & \multirow{3}{*}{ R:D } & m.p & \multicolumn{3}{|c|}{ Elemental analysis } \\
\hline & & $\left({ }^{\circ} \mathrm{C}\right)$ & \multicolumn{3}{|c|}{ Found (calcd \%) } \\
\hline & & & C & H & $\mathbf{N}$ \\
\hline TRZ-RBeng & \multirow{3}{*}{ 1:1 } & \multirow{3}{*}{248} & 33.08 & 3.14 & 5.94 \\
\hline$\left(\mathrm{C}_{39} \mathrm{H}_{27} \mathrm{Cl}_{4} \mathrm{I}_{4} \mathrm{~N}_{5} \mathrm{O}_{9}\right)$ & & & -34.36 & -2.2 & -5.14 \\
\hline Mol Mass=1359.06 & & & & & \\
\hline DOX-RBeng & \multirow{2}{*}{$1: 2$} & \multirow{2}{*}{232} & 41.4 & 3.12 & 6.8 \\
\hline$\left(\mathrm{C}_{66} \mathrm{H}_{52} \mathrm{Cl}_{4} \mathrm{I}_{4} \mathrm{~N}_{10} \mathrm{O}_{15}\right)$ & & & -42.28 & -2.793 & -7.473 \\
\hline
\end{tabular}

\begin{tabular}{|c|c|c|c|c|c|}
\hline Mol Mass=1874.62 & & & & & \\
\hline PIOG-RBeng & \multirow{3}{*}{$1: 2$} & \multirow{3}{*}{180} & 41.8 & 2.15 & 3.09 \\
\hline$\left(\mathrm{C}_{58} \mathrm{H}_{42} \mathrm{Cl}_{4} \mathrm{I}_{4} \mathrm{~N}_{4} \mathrm{O}_{11} \mathrm{~S}_{2}\right)$ & & & -42.32 & -2.509 & -3.325 \\
\hline Mol Mass $=1685.46$ & & & & & \\
\hline
\end{tabular}

Table 5: Analytical and physical data of RBeng-drug ion-pairs.

\section{FT-IR analysis}

The FT-IR of RBeng refers to the bands of $v(\mathrm{C}=\mathrm{O})$ stretching of the carboxylate at 1550.49 and $1492.63 \mathrm{~cm}^{-1}$, these bands are shifted to lower values of wavenumbers, (1540.85-1511.92 $\mathrm{cm}^{-1}$ and $\left.1490.7-1447.31 \mathrm{~cm}^{-1}\right)$, for the three drugs ion-pairs [30].

The FT-IR of TRZ refers to the bands of $v(\mathrm{C}=\mathrm{O})$ stretching of the amide at $1633.41 \mathrm{~cm}^{-1}$, and $v(\mathrm{C}-\mathrm{O})$ stretching of the hydro-furan ring at 1111.79 and $1078.98 \mathrm{~cm}^{-1}$ [30]. These bands are shifted to lower values of wavenumber in the corresponding TRZ-RBeng ion-pair, $v$ $(\mathrm{C}=\mathrm{O})$ stretching of the amide at $1627.63 \mathrm{~cm}^{-1}$ and $v(\mathrm{C}-\mathrm{O})$ stretching of the hydro-furan ring at $955.55 \mathrm{~cm}^{-1}$. The FT-IR of DOX refers to the bands of, $v(\mathrm{C}=\mathrm{O})$ stretching of the amide at $1635.34 \mathrm{~cm}^{-1}, v(\mathrm{C}-\mathrm{O})$ of the six membered ring at 1214.93 and $1171.54 \mathrm{~cm}^{-1}$ and $v$ (sulfoxide) stretching at $1042.34 \mathrm{~cm}^{-1}$ [30]. These bands are shifted to lower values of wavenumber in the corresponding DOX-RBeng ion-pair, $v(\mathrm{C}=\mathrm{O})$ stretching of the amide at $1631.48 \mathrm{~cm}^{-1}, v(\mathrm{C}-\mathrm{O})$ stretching of the six membered ring at 1108.87 and $1034.62 \mathrm{~cm}^{-1}$ and $v$ (sulfoxide) stretching is disappeared. The FT-IR of PIOG refers to the bands of $v$ 
(C-H) stretching of the aliphatic alkane at 2742.28 and $2615.97 \mathrm{~cm}^{-1}, v$ $(\mathrm{C}=\mathrm{O})$ stretching of the amide at 1742.37 and $1690.3 \mathrm{~cm}^{-1}$. These bands are shifted to lower values of wavenumber in the corresponding PIOG-RBeng ion-pair, $v(\mathrm{C}-\mathrm{H})$ stretching of the aliphatic alkane are disappeared, $v(\mathrm{C}=\mathrm{O})$ stretching of the amide at 1760.69 and 1701.87 $\mathrm{cm}^{-1}$. The data of the IR spectra of RBeng, the three drugs and their reaction products are listed in Table 6 .

The shift of the bands frequencies of some groups of the reagent and the drugs into lower and higher wavenumbers may be attributed to the electrostatic attraction between the cationic drugs and the anionic form of RBeng reagent.

These data confirm the proposed structures of drugs-RBeng ionpair in schemes (1-3).

\section{${ }^{1} \mathrm{H}-\mathrm{NMR}$ analysis}

The ${ }^{1} \mathrm{H}$-NMR spectra of RBeng; show two peaks with chemical shifts 7.410 and $7.912 \mathrm{ppm}$. These peaks appear in the ${ }^{1} \mathrm{H}-\mathrm{NMR}$ spectra of TRZ-RBeng ion-pair at chemical shifts 7.373 and 7.913 ppm; DOX-RBeng ion-pair at chemical shifts 7.395 and $7.918 \mathrm{ppm}$ and PIOG-RBeng ion-pair with a chemical shift range 7.394-7.713 ppm. This refers to the presence of RBeng in these ion-pairs.

The ${ }^{1} \mathrm{H}-\mathrm{NMR}$ spectra of TRZ; show peak with chemical shift 12.451 ppm; which corresponds to the proton of $\mathrm{NH}_{2}$ group and peak with chemical shift $8.620 \mathrm{ppm}$; which corresponds to the proton of $\mathrm{NH}+$ group. These peaks are shifted to $6.961 \mathrm{ppm}\left(\mathrm{H}\right.$ of $\mathrm{NH}_{2}$ group) or disappeared ( $\mathrm{H}$ of $\mathrm{NH}+$ group) in the $1 \mathrm{H}-\mathrm{NMR}$ spectra of TRZ-RBeng ion-pair. The ${ }^{1} \mathrm{H}-\mathrm{NMR}$ spectra of DOX show peak with chemical shift $11.725 \mathrm{ppm}$; which corresponds to the proton of $\mathrm{NH}_{2}$ group, two peaks with chemical shifts 8.702 and $8.812 \mathrm{ppm}$; which corresponds to the proton of $\mathrm{NH}+$ group and peak with chemical shift $2.328 \mathrm{ppm}$; which corresponds to $\mathrm{H}$ of the $\mathrm{CH}_{3}$ of the mesylate group. These peaks are shifted to $6.704 \mathrm{ppm}$ ( $\mathrm{H}$ of $\mathrm{NH}_{2}$ group) or disappeared ( $\mathrm{H}$ of $\mathrm{NH}+$ group and $\mathrm{H}$ of $\mathrm{CH}_{3}$ of the mesylate group) in the ${ }^{1} \mathrm{H}$-NMR spectra of DOX-RBeng ion-pair. The ${ }^{1} \mathrm{H}-\mathrm{NMR}$ spectra of PIOG; show peaks in the chemical shift range 7.929-8.698 ppm; which corresponds to the protons of pyridine ring. These peaks are shifted to $8.420 \mathrm{ppm}$ in the ${ }^{1} \mathrm{H}$-NMR spectrum of PIOG-RBeng ion-pair.

These changes in chemical shifts may be due to the electrostatic attraction between the cationic drugs and the bulky anionic reagent (small charge/unit volume); which is different from the electrostatic attraction between the cationic drugs and the small anionic part, chloride in case of TRZ and PIOG and mesylate in case of DOX, (has bigger charge/unit volume). These data confirm the proposed structure of drugs-RBeng ion-pair in schemes (1-3).

\begin{tabular}{|c|c|c|c|c|c|c|c|c|}
\hline Compound & $\begin{array}{l}\text { C-H streching of } \\
\text { aliphatic alkane }\end{array}$ & $\begin{array}{l}\mathrm{C}=\mathrm{O} \\
\text { streching } \\
\text { of the } \\
\text { amide }\end{array}$ & $\begin{array}{l}\mathrm{C}=\mathrm{O} \text { streching } \\
\text { of carboxylate }\end{array}$ & $\begin{array}{l}\text { C-N } \\
\text { streching }\end{array}$ & $\begin{array}{l}\text { C-O of six } \\
\text { membered } \\
\text { ring }\end{array}$ & $\begin{array}{l}\text { C-O streching } \\
\text { of hydrofuran } \\
\text { ring }\end{array}$ & $\begin{array}{l}\text { Sulfoxide } \\
\text { streching }\end{array}$ & $\begin{array}{l}\text { C-O Streching } \\
\text { of carboxylate }\end{array}$ \\
\hline RBeng & - & - & $\begin{array}{l}1550.49 \\
1492.63\end{array}$ and & - & - & - & - & 950.734 \\
\hline TRZ & $\begin{array}{l}2963.09 \quad \text { and } \\
2682.5\end{array}$ & 1633.41 & - & $\begin{array}{l}1283.39 \text { and } \\
1244.83\end{array}$ & - & $\begin{array}{l}1111.79 \\
1078.98\end{array} \quad$ and & - & - \\
\hline TRZ-RBeng Prod. & $\begin{array}{l}2929.34 \quad \text { and } \\
2364.3\end{array}$ & 1627.63 & $\begin{array}{l}1540.85 \\
1448.28\end{array}$ and & 1234.22 & - & 955.55 & - & 1107.9 \\
\hline DOX & 2943.8 & 1635.34 & - & $\begin{array}{l}1266.04 \\
1236.15\end{array}$ & $\begin{array}{l}1214.93 \\
1171.54\end{array}$ and & - & 1042.34 & - \\
\hline DOX-RBeng Prod. & 2928.38 & 1631.48 & $\begin{array}{l}1541.81 \text { and } \\
1490.7\end{array}$ & $\begin{array}{l}1261.22 \\
1233.25\end{array}$ & $\begin{array}{l}1108.87 \\
1034.62\end{array}$ and & - & disappeared & 985.447 \\
\hline PIOG & $\begin{array}{l}2742.28 \quad \text { and } \\
2615.97\end{array}$ & $\begin{array}{l}1742.37 \\
\text { and } 1690.3\end{array}$ & - & - & - & - & - & - \\
\hline PIOG-RBeng Prod. & disappeared & $\begin{array}{ll}1760 & 69 \\
\text { and } & \\
1701.87 & \end{array}$ & $\begin{array}{l}1511.92 \\
1447.31\end{array}$ and & - & - & - & - & 1041.37 \\
\hline
\end{tabular}

Table 6: FT-IR characteristic peaks of the drugs (TRZ, DOX and PIOG), RBeng reagent and their ion-pairs.

\section{Thermal analyses}

The TGA curve of RBeng shows that it decomposes in three steps. The first step may be related to the loss of $3 \mathrm{Cl}$ radicals. The second step may be related to the loss of $\mathrm{Na}_{2} \mathrm{CO}_{3}, 2 \mathrm{I}_{2}$ and $0.5 \mathrm{Cl}_{2}$. The third step may be related to the loss of $\mathrm{C}_{18} \mathrm{H}_{2} \mathrm{O}$ leaving $\mathrm{CO}$ as a remaining part.

The TGA of TRZ refers to the decomposition of this drug in three steps. The first step may be related to the loss of two water molecules. The second step may be attributed to the loss of $\mathrm{C}_{7} \mathrm{H}_{13} \mathrm{NO}_{2}$ radical. The third step may be attributed to the loss of $\mathrm{C}_{10} \mathrm{H}_{11} \mathrm{~N}_{3} \mathrm{O}_{2}$. $\mathrm{HCl}$ molecule.
It appears as strong exothermic peak in DTA; which may refers to chemical rearrangement and/or chemical recombination of the fragments to give the final formula. The TGA of TRZ-RBeng shows three steps of the thermal decomposition. The first step may be due to the loss of $\mathrm{Cl}_{2}$. The second step may be attributed to the loss of $\mathrm{C}_{14} \mathrm{H}_{18} \mathrm{~N}_{4} \mathrm{O}_{2}$ (from TRZ molecule). The third step is accompanied by two peaks at the DTA, endothermic peak and followed by exothermic one, so this step may occur at two stages. The first stage may be the loss of $\mathrm{Cl}_{2}$ and $2 \mathrm{I}_{2}$ and the second one may be the breaking of the ion pair 
Citation: Zayed MA, Farrag YS (2016) Spectroscopic Studies and Applications of the Reactions of Some Anti-Diabetic and Anti-Hypertensive Drugs with Rose Bengal. Pharm Anal Acta 7: 503. doi:10.4172/2153-2435.1000503

Page 8 of 10

which leads to the loss of $\mathrm{C}_{20} \mathrm{H}_{3} \mathrm{O}_{5}$ and formation of $\mathrm{C}_{5} \mathrm{H}_{9} \mathrm{NO}_{2}$ as a final residue.

The TGA of DOX shows that it decomposes in three main steps. The first step may be related to the loss of $\mathrm{C}_{11} \mathrm{H}_{11} \mathrm{NO}_{3}$ radical. The second step may be attributed to the loss of $\mathrm{C}_{2} \mathrm{H}_{7} \mathrm{~N} \cdot \mathrm{CH}_{3} \mathrm{O}_{3} \mathrm{~S}$. The third step may be attributed to the loss of $\mathrm{C}_{10} \mathrm{H}_{10} \mathrm{~N}_{2} \mathrm{O}_{2}$ molecule. It appears as strong exothermic peak in DTA; which may refers to chemical rearrangement and/or chemical recombination of the fragments to give the final Chemical formula. The TGA of DOX-RBeng refers to thermal decomposition in four steps. The first step may be due to the loss of $\mathrm{Cl}_{2}$. The second step may be attributed to the loss of $\mathrm{C}_{14} \mathrm{H}_{18} \mathrm{~N}_{4} \mathrm{O}_{2}$ (from one of DOX molecules). The third step may be attributed to the loss of $\mathrm{C}_{14} \mathrm{H}_{18} \mathrm{~N}_{4} \mathrm{O}_{2}$ (from the other DOX molecule) and the loss of $\mathrm{Cl}_{2}$ (from RBeng molecule). The fourth step is accompanied by two peaks at the DTA, endothermic peak and followed by exothermic one, so this step may occur at two stages. The first stage may be the loss of $2 \mathrm{I}_{2}$ and the second one may be the breaking of the ion pair which leads to the loss of $\mathrm{C}_{20} \mathrm{H}_{3} \mathrm{O}_{5}$ and $2 \mathrm{C}_{9} \mathrm{H}_{10} \mathrm{NO}_{3}$.

The TGA of PIOG shows that it decomposes in two main steps. The first step may be related to the loss of $\mathrm{CH}_{3}$ and $\mathrm{C}_{12} \mathrm{H}_{12} \mathrm{NO}_{3} \mathrm{~S}$. $\mathrm{HCl}$ radicals. The second step may be attributed to the loss of pyridine molecule $\mathrm{C}_{5} \mathrm{H}_{5} \mathrm{~N}$ leaving $\mathrm{CH}_{2}$ as a final residual. The TGA of PIOGRBeng ion-pair refers to thermal decomposition in two steps. The first step may be due to the breaking of the ion-pair and the loss of 2PIOG molecules. The second step is accompanied by two peaks at the DTA, small endothermic peak followed by strong exothermic one, so this step may occurs at two stages. The first stage may be the loss of $2 \mathrm{I}_{2}$ and $2 \mathrm{Cl}_{2}$ and the second one may be the loss of $\mathrm{C}_{19} \mathrm{H}_{12} \mathrm{O}_{2}$ and $\mathrm{CO}_{2}$ leaving $\mathrm{H}_{2} \mathrm{O}$ as a final part. Thermal Analyses results of the drugs (TRZ, DOX and PIOG), RBeng reagent and their ion-pairs are given in Table 7.

\section{Biological activity}

RBeng has a bacteriostatic action where it prevents the growth of some bacteria. The drugs under study are anti-hypertensive (TRZ and DOX) or anti-diabetic (PIOG) drugs, but they may also have some biological activity and adding RBeng to their structure may affects this activity. The biological activity of TRZ $\mathrm{HCl}$, DOX mesylate and PIOG $\mathrm{HCl}$ drugs and their solid ion-pairs with RBeng were determined using a modified Kirby-Bauer disc diffusion method towards two types of bacteria (Escherichia coli (G-) and Staphylococcus aureus (G+)) and two types of fungus (Aspergillus flavus and Candida albicans). Ampicillin was used as a reference compound for antibacterial activities and Amphotericin B was used as a reference compound for antifungal activities. Both the antibacterial and antifungal activities were evaluated by measuring the inhibition zone ( $\mathrm{mm} / \mathrm{mg}$ sample) (Table 8).

\begin{tabular}{|c|c|c|c|c|c|c|c|}
\hline \multirow[b]{2}{*}{ Compound } & \multirow{2}{*}{$\begin{array}{l}\text { TG range }{ }^{\circ} \mathrm{C}(\mathrm{DTGmax} \\
\left.{ }^{\circ} \mathrm{C}\right)\end{array}$} & \multirow[b]{2}{*}{ DTA $^{\circ} \mathrm{C}$} & \multicolumn{2}{|c|}{ Calcd (Estim) \% } & \multirow[t]{2}{*}{ Assignment } & \multirow{2}{*}{$\begin{array}{l}\text { Residue } \\
\text { (Estim) \% }\end{array}$} & \multirow{2}{*}{ Calcd. } \\
\hline & & & Mass loss & $\begin{array}{l}\text { Total mass } \\
\text { loss }\end{array}$ & & & \\
\hline \multirow[t]{3}{*}{ RBeng } & $35-214(65.27)$ & 114.1 endothermic & $10.46(11.14)$ & \multirow{3}{*}{$97.27(98.61)$} & Loss of $3 \mathrm{Cl}^{\circ}$ & \multirow{3}{*}{\multicolumn{2}{|c|}{ CO 2.75 (1.39) }} \\
\hline & $215-671(403.9)$ & 522.4 exothermic & $63.82(63.55)$ & & Loss of $\mathrm{Na}_{2} \mathrm{CO}_{3}, 2 \mathrm{I}_{2}$ and $\mathrm{Cl}$ & & \\
\hline & 671-954 (911.9) & 821.1 endothermic & $22.99(23.92)$ & & Loss of $\mathrm{C}_{18} \mathrm{H}_{2} \mathrm{O}$ & & \\
\hline \multirow[t]{3}{*}{ TRZ } & $72-139(114.1)$ & 117.9 endothermic & $7.827(6.765)$ & \multirow{3}{*}{$90.99(89.63)$} & Loss of $2 \mathrm{H}_{2} \mathrm{O}$ & \multirow{3}{*}{$\begin{array}{l}\mathrm{C}_{2} \mathrm{H}_{7} \mathrm{~N} \\
(10.37)\end{array}$} & \multirow{3}{*}{9.78} \\
\hline & $204-358(291.6)$ & 345.9 exothermic & $30.66(29.94)$ & & loss of $\mathrm{C}_{7} \mathrm{H}_{13} \mathrm{NO}_{2}$ & & \\
\hline & $358-640(564.1)$ & 558.7 exothermic & $52.51(54.65)$ & & Loss of $\mathrm{C}_{10} \mathrm{H}_{11} \mathrm{~N}_{3} \mathrm{O}_{2} \cdot \mathrm{HCl}$ & & \\
\hline \multirow{4}{*}{$\begin{array}{l}\text { TRZ-RBeng ion- } \\
\text { pair }\end{array}$} & $47-150(59.91)$ & 63.64 exothermic & $5.22(4.32)$ & \multirow{4}{*}{$91.66(92.41)$} & Loss of $\mathrm{Cl}_{2}$ & \multirow{4}{*}{$\begin{array}{l}\mathrm{C}_{5} \mathrm{H}_{9} \mathrm{NO}_{2} \\
(8.13)\end{array}$} & \\
\hline & $150-277(244.4)$ & 239.9 exothermic & $20.16(21.17)$ & & $\begin{array}{l}\text { Loss of } \mathrm{C}_{14} \mathrm{H}_{18} \mathrm{~N}_{4} \mathrm{O}_{2} \\
\text { molecule) }\end{array}$ & & 8.46 \\
\hline & \multirow{2}{*}{$277-632(585.8)$} & 506.7 endothermic & \multirow{2}{*}{$67.03(66.17)$} & & Loss of $\mathrm{Cl}_{2}, 2 \mathrm{I}_{2}$ & & \\
\hline & & 588.2 exothermic & & & Loss of $\mathrm{C}_{20} \mathrm{H}_{12} \mathrm{O}_{5}$ & & \\
\hline \multirow[t]{3}{*}{ DOX } & $218-350(319.3)$ & 347.4 endothermic & $37.47(35.33)$ & \multirow{3}{*}{$96.90(94.75)$} & Loss of $\mathrm{C}_{11} \mathrm{H}_{11} \mathrm{NO}_{3}$ & \multirow{3}{*}{\multicolumn{2}{|c|}{$\mathrm{NH}_{3} 3.10(5.54)$}} \\
\hline & $350-482(414.6)$ & 432.8 exothermic & $25.57(24.09)$ & & Loss of $\mathrm{C}_{2} \mathrm{H}_{7} \mathrm{~N} \cdot \mathrm{CH}_{3} \mathrm{O}_{3} \mathrm{~S}$ & & \\
\hline & $482-659(598.9)$ & 603.6 exothermic & $34.68(35.33)$ & & Loss of $\mathrm{C}_{10} \mathrm{H}_{10} \mathrm{~N}_{2} \mathrm{O}_{2}$ & & \\
\hline \multirow{4}{*}{$\begin{array}{l}\text { DOX-RBeng ion- } \\
\text { pair }\end{array}$} & $63-174(75.34)$ & 82.61 exothermic & $3.79(3.19)$ & \multirow{4}{*}{$100(99.39)$} & Loss of $\mathrm{Cl}_{2}$ & \multirow{4}{*}{\multicolumn{2}{|c|}{-}} \\
\hline & $174-260(249.8)$ & 241.7 exothermic & $14.62(14.77)$ & & $\begin{array}{l}\text { Loss of } \mathrm{C}_{14} \mathrm{H}_{18} \mathrm{~N}_{4} \mathrm{O}_{2} \text { (from one of } \\
\text { DOX molecules) }\end{array}$ & & \\
\hline & $260-350(304.3)$ & 267.8 exothermic & $18.40(17.38)$ & & $\begin{array}{l}\text { Loss of } \mathrm{C}_{14} \mathrm{H}_{18} \mathrm{~N}_{4} \mathrm{O}_{2} \text { (from the other } \\
\text { DOX molecule) and } \mathrm{Cl}_{2} \text { (form RBeng } \\
\text { molecule) }\end{array}$ & & \\
\hline & $350-651(572.39)$ & 547.6 endothermic & $63.53(64.05)$ & & Loss of $2 \mathrm{I}_{2}$ & & \\
\hline
\end{tabular}


Citation: Zayed MA, Farrag YS (2016) Spectroscopic Studies and Applications of the Reactions of Some Anti-Diabetic and Anti-Hypertensive Drugs with Rose Bengal. Pharm Anal Acta 7: 503. doi:10.4172/2153-2435.1000503

Page 9 of 10

\begin{tabular}{|c|c|c|c|c|c|c|}
\hline & & 635.8 exothermic & & & Loss of $2 \mathrm{C}_{9} \mathrm{H}_{10} \mathrm{NO}_{3}$ and $\mathrm{C}_{20} \mathrm{H}_{3} \mathrm{O}_{5}$ & \\
\hline \multirow[t]{2}{*}{ PIOG } & 68-334 (291.9) & 299.0 endothermic & $76.61(75.53)$ & \multirow{2}{*}{$96.72(95.24)$} & Loss of $\mathrm{CH}_{3}$ and $\mathrm{C}_{12} \mathrm{H}_{12} \mathrm{NO}_{3} \mathrm{~S} . \mathrm{HCl}$ & \multirow{2}{*}{$\mathrm{CH}_{2} 3.56(4.76)$} \\
\hline & $410-600(537.0)$ & 533.0 exothermic & $20.11(19.71)$ & & Loss of $\mathrm{C}_{5} \mathrm{H}_{5} \mathrm{~N}$ & \\
\hline \multirow{3}{*}{$\begin{array}{l}\text { PIOG-RBeng ion- } \\
\text { pair }\end{array}$} & $40-309(284.0)$ & 178.4 exothermic & $42.36(43.36)$ & \multirow{3}{*}{$99.67(98.40)$} & Loss of 2PIOG molecules & \multirow{3}{*}{$\mathrm{H}_{2} \mathrm{O} 1.07$ (1.31) } \\
\hline & \multirow{2}{*}{$309-584(483.9)$} & 341.6 endothermic & \multirow{2}{*}{$57.28(55.04)$} & & $2 \mathrm{I}_{2}$ and $2 \mathrm{Cl}_{2}$ & \\
\hline & & 497.7 & & & Loss of $\mathrm{CO}_{2}$ and $\mathrm{C}_{19} \mathrm{H}_{12} \mathrm{O}_{2}$ & \\
\hline
\end{tabular}

Table 7: Thermal Analyses results of the drugs (TRZ, DOX and PIOG), RBeng reagent and their ion-pairs.

\begin{tabular}{|l|l|l|l|l|}
\hline & \multicolumn{2}{|l|}{ Antimicrobial effect (\% relative to Ampicillin) } & \multicolumn{2}{l|}{ Antifungal effect (\% relative to Amphotericin B) } \\
\hline Sample & Escherichia coli (G) & Staphylococcus aureus (G+) & Aspergillus flavus & Candida albicans \\
\hline TRZ & 45.45 & 55.56 & 0.00 & 47.37 \\
\hline TRZ-RBeng & 72.73 & 94.44 & 0.00 & 0.00 \\
\hline PIOG & 0.00 & 0.00 & 0.00 & 0.00 \\
\hline PIOG-RBeng & 63.64 & 83.33 & 0.00 & 0.00 \\
\hline DOX & 54.55 & 72.22 & 0.00 & 63.16 \\
\hline DOX-RBeng & 54.55 & 66.67 & 0.00 & 0.00 \\
\hline
\end{tabular}

Table 8: Comparison between the biological activity of standard drugs and their products with RBeng.

From Table 8; it is found that the antibacterial activities of TRZ and PIOG increased after adding RBeng to their structures. It is found that TRZ-RBeng and PIOG-RBeng ion-pairs are biologically more active than the parent drugs. The antibacterial activity toward $E$. coli and $S$. aureus, in comparison with the standard found in the local market (Ampicillin), are $72.73 \%$ and $94.44 \%$ (for TRZ-RBeng ion-pair), 63.64\% and $83.33 \%$ (for PIOG-RBeng ion-pair), respectively. DOXRBeng ion-pair has almost the same bacterial activity of the parent drug. Increasing the biological activity of the products refers to the biological activity of RBeng itself found in their entities. From studying the antifungal activity of the drugs, it is found that, only TRZ and DOX, have antifungal activity toward $C$. albicans, in comparison with the standard found in the local market (Amphotericin B) $(47.37 \%$ and $63.16 \%$ respectively). It is can be concluded that the drugs under study and their solid ion-pairs with RBeng are more antibacterial agents than antifungal agents.

\section{Conclusion}

This manuscript involved fast (not time consuming), cheap and reliable spectrophotometric procedures for the determination of TRZ $\mathrm{HCl}$, DOX mesylate and PIOG $\mathrm{HCl}$ drugs depending on color reactions between them and a chromogenic reagent (RBeng). The solid reaction products were prepared, separated and characterized by elemental, spectroscopic (FT-IR, ${ }^{1} \mathrm{H}$ NMR) and thermal techniques. Antibacterial activity of the drugs and their reaction products with RBeng were tested by diffusion agar method and compared with each other. It is found that TRZ-RBeng and PIOG-RBeng reaction products have antimicrobial effect higher than the parent drugs, but DOXRBeng reaction product has almost the same antimicrobial effect of the parent drug. Increasing the antimicrobial effect of the products refers to the antimicrobial effect of RBeng itself in their entities. It is also found that the drugs and their solid ion-pairs with RBeng are more antibactrial agents than antifungal agents.

\section{References}

1. (2009) British Pharmacopoeia Her Majesty's Stationary Office, London,UK.

2. O'Neil MJ, Heckerman PE, Koch CB, Roman KJ (2006) The Merck Index (14th edn) Merck \& Co, Inc, Whitehouse Station, NJ, USA: 581.

3. Sekhar EC, Rao TRK, Sekhar KR, Naidu MUR, Shobha JC (1998) Determination of Terazosin in Human Plasma Using High Performance Liquid Chromatography With Fluorescence Detection. J Chromatogr B: Biomed Appl 710: 137-142.

4. Bakshi M, Ojhaa T, Singh S (2004) Validated Specific HPLC Methods for Determination of Prazosin, Terazosin and Doxazosin in the Presence of Degradation Products Formed Under ICH-Recommended Stress Conditions. JPBA 34: 19-26.

5. Sheikh R El, Esmail NS, Gouda AA, Abdel Basset W (2012) Extractive Spectrophotometric Determination of Some a-Adrenergic-Antagonists in Pure Forms and in Pharmaceutical Formulations, CI \& CEQ 18: 179-191.

6. Ganjali MR, Shams H, Faridbod F, Hajiaghababaei L, Norouzi P (2009) Lanthanide Recognition: A Ho (III) Potentiometric Membrane Sensor as A Probe for Determination of Terazosin, Mater Sci Eng C 29: 1380-1386.

7. Ghoneim MM, Ries MA El, Hammama E, Beltagi AM (2004) A Validated Stripping Voltammetric Procedure for Quantification of The AntiHypertensive and Benign Prostatic Hyperplasia Drug Terazosin in Tablets and Human Serum. Talanta 64: 703-710.

8. Dhanya B, Suganthi A, Sen AK, Sahoo U, Seth AK (2011) Determination of Doxazosin Mesylate in Tablets by RP-HPLC, Indian J Pharm Sci 73: $120-122$. 
Citation: Zayed MA, Farrag YS (2016) Spectroscopic Studies and Applications of the Reactions of Some Anti-Diabetic and Anti-Hypertensive Drugs with Rose Bengal. Pharm Anal Acta 7: 503. doi:10.4172/2153-2435.1000503

Page 10 of 10

9. Ma N, Liu W, Li H, Chen B, Zhu Y (2007) LC-MS Determination and Relative Bioavailability of Doxazosin Mesylate Tablets in Healthy Chinese Male Volunteers. J Pharm Biomed Anal 43: 1049-1056.

10. Ali AAA, Elbashir AA (2013) A New Spectrophotometric Method for the Determination of Cardiovascular Drugs in Dosage Forms. AASR J 5: 106-121.

11. SF de Beton o, Garcia AA (1999) UV-Spectrophotometry and Square Wave Voltammetry at Nafion-Modified Carbon-Paste Electrode for the Determination of Doxazosin in Urine and Formulations. J Pharm Biomed Anal 20: 621-630.

12. Ho ENM, Yiua KCH, Wana TSM, Stewartb BD, Watkins KL (2004) Detection of Anti-Diabetics in Equine Plasma and Urine by Liquid Chromatography-Tandem Mass Spectrometry. J Chromatogr B Analyt Technol Biomed Life Sci 811: 65-73.

13. Yamashita K, Murakami H, Teruaki O and Motohashi M (1996) HighPerformance Liquid Chromatographic Determination of Pioglitazone and Its Metabolites in Human Serum and Urine. J Chromatogr B Anal Technol Biomed Life Sci 677: 141-146.

14. Lin ZJ, Ji W, D D. Krieger, Shum L (2003) Simultaneous Determination of Pioglitazone and Its Two Active Metabolites in Human Plasma by LCMS/MS, J Pharm Biomed Anal 33: 101-108.

15. Amanlou M, Ghobadi MZ, Rofouei MK (2010) Extractive Spectrophotometric Method for Determination of Pioglitazone $\mathrm{HCl}$ in Raw Material and Tablets Using Ion-Pair Formation. J Chem 7: 915-921.

16. Mostafa GAE, Al-Majed A (2008) Characteristics of New Composite and Classical Potentiometric Sensors for the Determination of Pioglitazone in Some Pharmaceutical Formulations. J Pharm Biomed Anal 48: 57-61.

17. Al-Arfaj NA, Al-Abdulkareem EA, Aly FA (2008) A Validated Adsorptive Stripping Voltammetric Determination of Antidiabetic Agent Pioglitazone $\mathrm{HCl}$ in Tablets and Biological Fluids. Int J Biomed Sci 4: 310-318.

18. Mousavi SH, Afshari JT, Brook A, Anarkooli IJ (2009) Direct Toxicity of Rose Bengal in MCF-7 Cell Line: Role of Apoptosis. Food Chem Toxicol 47: 855-859.
19. Amin AS, E1-Henawee MM (1995) Colorimetric Method for the Simultaneous Determination of Chlorophenoxamine Hydrochloride and Anhydrous Caffeine in Pure and Dosage Forms with Rose Bengal. Mikrochim Acta 118: 177-183.

20. Raut KN, Sabnis SD (1987)A New Spectrophotometric Method for Estimation of Ranitidine Hydrochloride. Indian J Pharm Sci 49: 65-66.

21. Britton HTS (1952) Hydrogen Ions (4th edn) Chapman and Hall, London.

22. Vosburgh WC, Cooper GR (1941) Complex Ions- I- The Identification of Complex Ions in Solution by Spectrophotometric Measurements, J Am Chem Soc 63: 437-442.

23. Yoe JH, Jones AL (1944) Colorimetric Determination of Fe with Disodium 1, 2 Dihydroxybenzene-3, 5- Disulfonate. Ind Eng Chem Anal Ed 16: 111-115.

24. Ammar RA, El-Brashy AM, Al-Sahly TN (2014) Spectrophotometric and Spectrofluorimetric Determination of Doxazosin Mesylate in Tablets via Eosin Y. Asian J Chem 26: 57-62.

25. Basniwal PK, Srivastava PK, Jain D (2008) Spectrophotometric Estimation of Pioglitazone Hydrochloride in Tablet Dosage Form, Asian J Pharmac 2: 225-227.

26. Miller JN, Miller JC (2010) Statistics and Chemometric for Analytical Chemistry, 6th edition, Pearson Education Limited, England: 266.

27. Socrates G (2004) Infrared and Raman Characteristic Group Frequencies: Tables and Charts John Wiley \& Sons: 18.

28. Abd Elbary A, Kassem MA, Abou Samra MM, Khalil RM (2008) Formulation and Hypoglycemic Activity of Pioglitazone-Cyclodextrin Inclusion Complexes. Drug Discov Ther 2: 94-107.

29. Zayed MA, Fahmey MA, El-Desawy M, Farrag YS (2015) Structure characterization of terazosin drug using mass spectrometry and thermal analyses techniques in comparison with semi-empirical molecular orbital (MO) calculations. J Therm Anal Calorim 120: 1061-1069.

30. Smith NR, Dawson VT (1944) The Bacteriostatic Action Of Rose Bengal In Media Used For Plate Counts Of Soil Fungi. Soil Science 58: 467-472 